\title{
Longitudinal Assessment of Illness Perceptions in Young Adults with Cancer
}

\author{
Avaliação Longitudinal da Percepção da Doença em Adultos Jovens com Câncer
}

\author{
Elisa Kern de Castro ${ }^{*}$, , Marina Kreling ${ }^{a}$, Clarissa Ponciano ${ }^{a}$, \\ Bruna Machado Meneghetti ${ }^{a} \&$ Carolina Mainieri Chem ${ }^{b}$ \\ ${ }^{a}$ Universidade do Vale do Rio dos Sinos, São Leopoldo, Brasil \& ${ }^{b} H o s p i t a l$ Santa Rita, Porto Alegre, Brasil
}

\begin{abstract}
The purpose of this study was to assess longitudinally the illness perception in young adults with cancer. Participants were 50 patients who answered socio-demographic and clinical data questionnaires and the Brief Illness Perception Questionnaire (Brief IPQ). Longitudinal results revealed no significant changes in illness perceptions over one-year period. However, perceptions about cancer causality were significantly different in the same period. Women presented more negative cognitive perceptions about cancer than men in Time 1 (T1), but in T2 women revealed more negative emotional perceptions about the cancer. It was concluded that illness perception over one-year period remained relatively stable, but there are strong evidence for differences between men and women.

Keywords: Illness perception, coping, cancer, adult.

Resumo

O objetivo deste estudo foi avaliar longitudinalmente a percepção da doença em adultos jovens com câncer Os participantes foram 50 pacientes que responderam questionários sócio-demográficos e de dados clínicos e o Questionário de Percepção Breve de Doença (Brief IPQ). Os resultados longitudinais não revelaram alterações significativas nas percepção da doença ao longo do período de um ano. No entanto, percepções sobre a causalidade do câncer foram significativamente diferentes no mesmo período. As mulheres apresentaram mais percepções cognitivas negativas sobre o câncer do que os homens no Tempo 1 (T1), já no T2 as mulheres revelaram mais percepções emocionais negativas a respeito do câncer. Concluiu-se que a percepção da doença ao longo de um período de um ano permaneceu relativamente estável, mas existem fortes evidências de diferenças entre homens e mulheres.

Palavras-chave: percepção da doença, enfrentamento, câncer, adulto.
\end{abstract}

Illness perception, according to the Health Self-regulation model (Leventhal, Brissete, \& Leventhal, 2003; Leventhal, Nerenz, \& Steele, 1984), is referred to the way how the individual thinks about his health problem and, consequently, how he behaves. In this model are considered the perceptions and expectations that individual has about his disease or it's somatic symptoms and the cognitive representations available for the individual, related to his health problem (Covic, Seica, Gusbeth-Tatomir, Gavilovrici, \& Goldsmith, 2004). The person's health problem will induce, in term, emotional answers which will tend to increase or diminish the intensity of his problem's symptoms (Shaw, 1999). The representational content is directly related to the person's nature and perception about how much the disease will threaten his health. Therefore,

* Endereço para correspondência: Centro de Ciências da Saúde, Universidade do Vale do Rio dos Sinos, Avenida Unisinos, 950, Sala 2B112, Cristo Rei, São Leopoldo, RS, Brasil, 93022-000. E-mail: elisa.kerndecastro@gmail.com, marinakreling@gmail.com, clarissa.ponciano@gmail.com, meneghetti.b@gmail.com e carolinachem@hotmail.com the illness perceptions will guide the individual's behavior in various aspects of his life, including his way of coping with the illness (Heijmans \& Ridder, 1998; Petrie \& Weinman, 2006).

According to that model, there are five dimensions of illness perception (Leventhal et al., 1984): (a) identity or how much the person believes that the disease and its symptoms are threatning his identity; (b) timeline, or how much time the person believes that the disease will take to develop and for him to recover from it; (c) cause or what the person believes may have been the reasons for his illness; (d) consequences or how much the person realizes the consequences of his sickness in his daily life, may it be real or imaginary; (e) cure or control, this is, the perception of which degree the disease can be treated or cured. This dimensions followed a logical model supported by the construct and discriminant validity among the various kinds of diseases that were originally evaluated with IPQ - Illness Perception Questionnaire measure (Weinman, Petrie, Moss-Morris, \& Horne, 1996) revised by Moss-Morris et al. (2002). Later, it was also developed 
a brief measure in order to evaluate illness perception in three dimensions: cognitive, emotional and illness comprehension. These dimensions also presented adequated psychometric properties (Broadbent, Petrie, Main, \& Weinman, 2006).

The representations differ from illness knowledge because of it's flexibility, meanwhile knowledge reflects objective data acquired through the medical team or others sources of information (Shiloh, 2006). According to the author, it is common to find people who can answer correctly to a knowledge test about their illness and, at the same time, express personal beliefs and understandings about their conditions which deviate from the acquired knowledge. Being so, the representations about a certain disease may vary, including among patients who suffer from the same pathology (Heijmans \& Ridder, 1998). In this sense, evaluation of the patient's perception may help them to interpret his sense of the disease and how to cope with the problems caused by it, facilitating his self-regulation.

The cognitive and emotional perceptions that the person has about his health problem, specially in relation with chronic diseases such as cancer, are related to the quality of life, in the way that his actions could intensify the negative symptoms of his problem (for example, increase of pain), or improve his prognosis (Figueras \& Marcelino, 2009). That way, when illness perceptions are mostly negative, the person will tend to have a deeper feel of his condition's symptoms, to believe that the disease will last for a longer period and that the recovery, if happens, will be slow (Petrie \& Weinmann, 2006). This perceptions, according to these authors, may be changed throug the guidance in using effective coping strategies.

Cancer perceptions, specifically, are receiving a growing attention in international literature over past few years. These studies investigate perceptions of patients with diagnose of different cancer types (Anagnostopoulos \& Spanea, 2005; Llevellyn, McGurk, \& Weinman, 2007; Millar, Purushotham, McLatchie, George, \& Murray, 2005; Scharloo et al., 2005), representations of people with genetic risk of cancer (Rees, Fry, Cull, \& Sutton, 2004) and, also, cancer survivals (Rees et al., 2004). Research about this theme and groups of patients was not found in Brazilian literature.

In respect to the studies about illness perceptions in patients with cancer diagnosis that used longitudinal assessment, Llevellyn et al. (2007) examined longitudinally (6-8 months) the role of representations about the influence of the disease on the prediction of quality of life and psychologycal symptoms in 50 patients with neck and head cancer. Cancer perceptions and treatment were not predictors of quality of life and anxiety 6-8 months after beginning the treatment. Meanwhile, the belief about disease chronicity was predictive of depression in that period. The authors enhance the importance of the representations for mid-term psychological results, but they also say that it is important to keep in mind that this is a dynamic process that can be altered by the course of the disease and its treatment. Fairly similar results were also found by Millar et al. (2005), on their longitudinal evaluation (one year) of illness perceptions and psychological morbities in 371 breast cancer patients. Although the authors observed a reduction of psychological morbity within one year after mastectomy, $25 \%$ of those patients mantained stable levels of psychological stress during the period. The psychological stress was explained essencially by the level of post-operatory stress, by the perceived symptoms of the disease, the believe of chronicity, general health and, on a lesser extent, by the dimension of neuroticism personality.

Stress may reduce the quality of life of a cancer patient, specially if he is a young adult. This statement can be confirmed in the young women with breast cancer, when compared to old women with the same disease (Baucom, Porter, Kirby, Gremore, \& Keefe, 2006; Kissane et al., 2004). Effects of the treatments that are applied on them, like mastectomy, chemotherapy and radiotherapy, seem to have a bigger impact on young patients in relation to their body image, precaucious menopause, diminishing sexual desire and, consequently, changes in the conjugal behavior from both partners.

Other cross-sectional studies about cancer perceptions can be found in international literature, that show the importance of this concept on the patient's health. Rozema, Völlink and Lechner (2009) investigated the relation between illness perceptions, coping and perceived health status of 119 breast cancer patients. Results show that the dimensions of identity and consequences explained $57 \%$ of the physical health variance, meanwhile the emotional representations and treatment control explained $47 \%$ of the mental health. Disease's clinical and treatment variables and coping were not predictive of the health results in those patients. Scharloo et al. (2005), in their turn, investigated the predictive role of illness perceptions on the quality of life of 68 patients recently diagnosed with head and neck cancer. Their results showed the correlation between perceptions and every dimension evaluated about the quality of life (physical, emotional and social relations). There is a tendence to have worst quality of life in patients who had increased attention to the illness symptoms, who believe in the chronicity and reincidence of it, who were more susceptible to self-blaming and who had negative strong emotional reactions. Anagnostopoulos and Spanea (2005) examined perceptions of breast cancer on patients with and without the disease. Results showed disparity between the perception of healthy women and women with cancer. The first group was characterized by weak beliefs, about the role of environmental factors (radiation exposure, diet, polution) towards the development of breast cancer and expressed huge disagreement on its role of the development and mantaince of the disesase in relation with the women carrying the disease, in this sense sick women were more realistic. Rees et al. (2004) evaluated the relation between 
Castro, E. K., Kreling, M., Ponciano, C., Meneghetti, B. M. \& Chem, C. M. (2012). Longitudinal Assessment of Illness Perceptions in Young Adults with Cancer.

breast cancer perception and the feeling of women with risk factor of developing the disease. The study showed that women who presented a significant believe that they would develop cancer in their life time were the same who had bigger risk of developing cancer.

The study of Jorgensen, Frederiksen, Boesen, Elsass and Johansen (2009), evaluated 177 women who survived breast cancer, half of them were chosen at random to participate in a psychosocial rehabilitation program and the other half received standard treatment whithout other kind of intervention. The results showed, from the filling of questionnaires about illness perception two and a half weeks and six months after the study, that there were not significant changes in the perception of women that were on the rehabilitation group and those who were not part of the group.

Considering the importance of illness perception on the psychological adaptation in cancer patients, specially in young patients, and the non existence of Brazilian studies about that theme, it becomes relevant the knowledge, in our reality, of how the perceptions of cancer patients show up whithin this context. Thus, the purpose of the present study was to examine longitudinally (one year) the illness perception in young adults with cancer, observing, also, possible differences between men and women.

\section{Method}

\section{Design}

Longitudinal - T1 (Time 1, year of 2008) and T2 (Time 2, year of 2009, twelve months after the first data collection).

Table 1

Biossociodemographic and Clinical Data of Patients with Câncer in T1 and T2 (n=50)

\begin{tabular}{lrr}
\hline & $\mathrm{T} 1$ & $\mathrm{~T} 2 n(\%)$ \\
& $n(\%)$ & $n(\%)$ \\
\hline Gender & $17(34 \%)$ & $17(34 \%)$ \\
$\quad$ Male & $33(66 \%)$ & $33(66 \%)$ \\
$\quad$ Female & & $21(42 \%)$ \\
Schoolarity & $21(42 \%)$ & $6(12 \%)$ \\
$\quad$ Basic incomplete & $6(12 \%)$ & $6(12 \%)$ \\
$\quad$ Basic complete & $6(12 \%)$ & $11(22 \%)$ \\
$\quad$ Secundary incomplete & $11(22 \%)$ & $6(12 \%)$ \\
$\quad$ Secundary complete & $6(12 \%)$ & $18(36 \%)$ \\
University incomplete & & $31(62 \%)$ \\
Marital Status & $17(34 \%)$ & $1(2 \%)$ \\
$\quad$ Single/Divorced & $33(66 \%)$ & $15(30 \%)$ \\
$\quad$ Warried/In a relationship & & $32(72 \%)$ \\
With methastasis & $12(24 \%)$ & $18(36 \%)$ \\
With family cancer history & $32(72 \%)$ & $8(16 \%)$ \\
With chemotherapy in the last year & $30(60 \%)$ & $17(34 \%)$ \\
With radiotherapy in the last year & $23(46 \%)$ & $44(88 \%)$
\end{tabular}

\section{Participants}

Participants were young adults with several types of cancer under ambulatory treatment in a major oncology Grande do Sul, Brazil. Those patients were part of a larger study which evaluated the quality of life and psychological aspects of 152 young adult patients with cancer and who were selected in a consecutive way among those who fullfilled the inclusion criteria (cancer diagnosis, in treatment at least for one month, between 18-40 years of age). Patients who were diagnosed with benign tumors were excluded. The present study was carried out with 50 participants, 33 women and 17 men, who participated in the first data collection (T1) and answered to the same questionnaires one year after the first collection (T2). About the other participants of the initial sample and who were not part of this study, 12 died in hospital and 90 were not located. It is possible that some of those 90 patients have also died since they did not return to the doctor and was not possible to establish contact by phone. However, was not possible to confirm how many of them would have died, abandoned the treatment or changed the treatment location.

The most common cancer types in that sample were: breast cancer (16 patients), rectum carcinom (4), uterus carcinom (4), melanom (3), sarcom (3), mouth carcinom (3), and other types (17). The average age of the patients in T1 was $33.3(S D=5.60)$, and the average on the disease diagnosis was $30.5(S D=6.30)$. All the patients were in treatment through the National Health System (Sistema Único de Saúde [SUS]) and did not participate in psychological or psychosocial programs. Table 1 shows the biossociodemographic data of the sample: reference hospital located in Porto Alegre, capital of Rio year 2009 , twelvemonths after the first datacollection). 


\section{Ethical and Data Collection Procedures}

Data collection was performed in the hospital between April and October 2008 (T1) and April and October 2009 (T2). The patients who were waiting for routine medical appointments and filled the inclusion criteria were invited to take part in the study. Data collection was made in an ambulatory room in the hospital by scientific iniciation schoolarship students. They read the questions for the patients and filled up the answers, since most of them had reading problems due to low schoolarity level.

\section{Questionnaires}

Sociodemographic and Clinical Data File. Contained questions related to patient personal data (name, birth date, marital status, schoolarity, among others) and data about the disease (type of cancer and treatments used: chemotherapy, radiotherapy and surgery), family history about cancer, among other information. That data was collected from the patients files.

Illness Perception Questionnaire - Brief version (Broadbent et al., 2006). Questionnaire with nine questions developed from the questions that made a better synopsis of the items contained in the subscales of the original 100 items questionnaire (Moss-Morris et al., 2002). All the items are evaluated on a scale from 0 to 10 , with exception of the causal representation, which is evaluated with semiopen adapted questions of the IPQ-R, which ask the patients to list the three causal factors with more importance for the disease (Item 9). The answers to that item can be grouped in a posteriori categories. High scores in the eight closed questions indicate negative ilness perceptions. Five items in the questionnaire evaluate the cognitive perception of the disease: consequences (item 1), timeline (item 2), personal control (item 3), treatment control (item 4) and identity (item 5). Two items evaluate emotional perception: concern about the illness (item 6) and disease generated emotions (item 8). One item evaluates the comprehension of the disease (item 7). The brief ques- tionnaire construction's study was made in New Zealand with 891 varied chronical patients and the Chronbach alpha was .91. The Portuguese version of the questionnaire was made by Araújo-Soares, Trovisqueira e McIntyre, and is available in the questionnaire's official site (http://www.uib.no/ipq). The alpha .66 in T1 and .68 in T2 was found for the eight items in the likert scale of the questionnaire in the present study.

\section{Data Analysis}

Based on research data, psychometric properties of the questionnaire and verification of normal distribution of the sample was analyzed by Kolmogorov-Smirnoff test. Paired $t$ test was used to evaluate possible differences of illness representation between $\mathrm{T} 1$ and $\mathrm{T} 2$. An independent $t$ test was used to verify possible differences between men and women in illness perception. Pearson correlation was used to examine the relation between sociodemographic variables and illness representation. A content analysis of the answers was performed in order to establish tematic categories of the questionnaire's open question about the causes of cancer (Bardin, 1977) and each one's frequencies computed. Chi-square test was used in sequence in order to discover possible differences in those answers between $\mathrm{T} 1$ and $\mathrm{T} 2$ and between men and women. It was considered significant the value of $p<.05$.

\section{Results}

As per Figure 1, in $\mathrm{T} 1$ the patients had larger averages for emotional perception and illness comprehension and smaller averages for cognitive perception in comparison with T2, but those differences were not significant. Paired $t$ test was also performed comparing the results between $\mathrm{T} 1$ and $\mathrm{T} 2$ splitting the sample by gender, however, there was not significant differences found on the perception of one year.

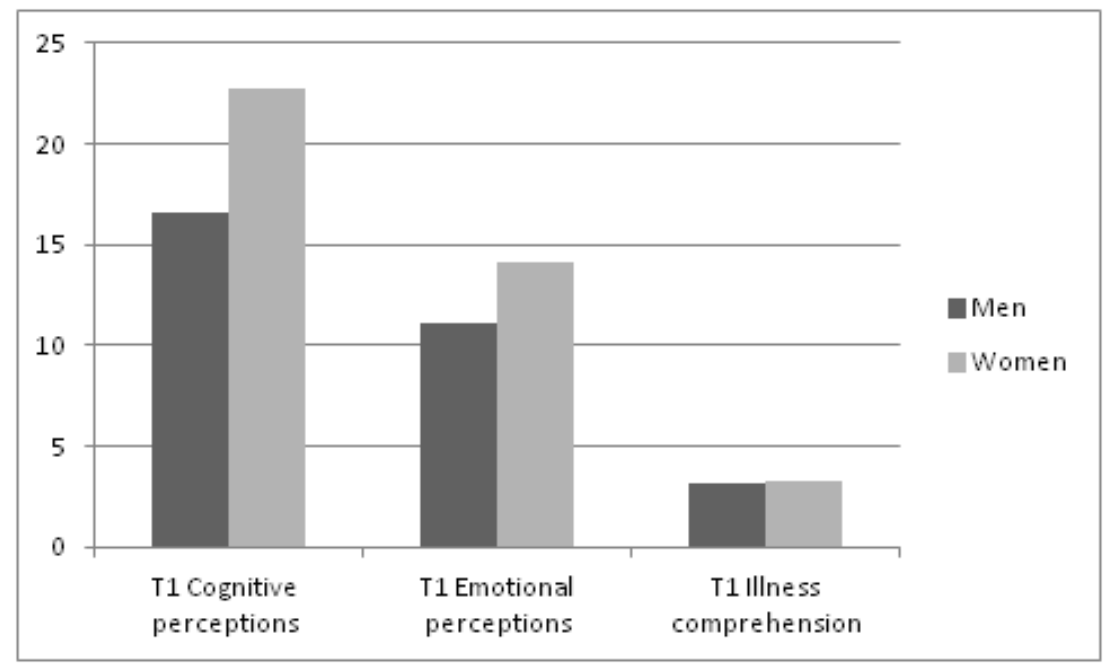

Figure 1. Average comparison (Paired $t$-test) of cognitive and emotional perceptions and illness comprehension among patients with cancer between T1 and T2 $(n=50)$. 
With relation to the particularities in cancer perceptions according to gender, it is possible to check in Figure 2 that women have bigger average than men in the three dimension of illness perception both in $\mathrm{T} 1$ and $\mathrm{T} 2$, indicating more negative illness perceptions. An independent $t$ test revealed that those differences were significant in what refers to cognitive perceptions in $\mathrm{T} 1(t=-2.551, p<.05)$, indicating that women believed to have less control on the disease and treatment, that their disease would last for longer and would have more negative consequences, and still, that their identity was more affected by cancer than men. In T2, gender differences showed up in the emotional representations, were women had more concern and negative emotions conditions than men $(t=-2.019$, $p<.05$ ). Figure 2 illustrate the answers of patients according to gender.

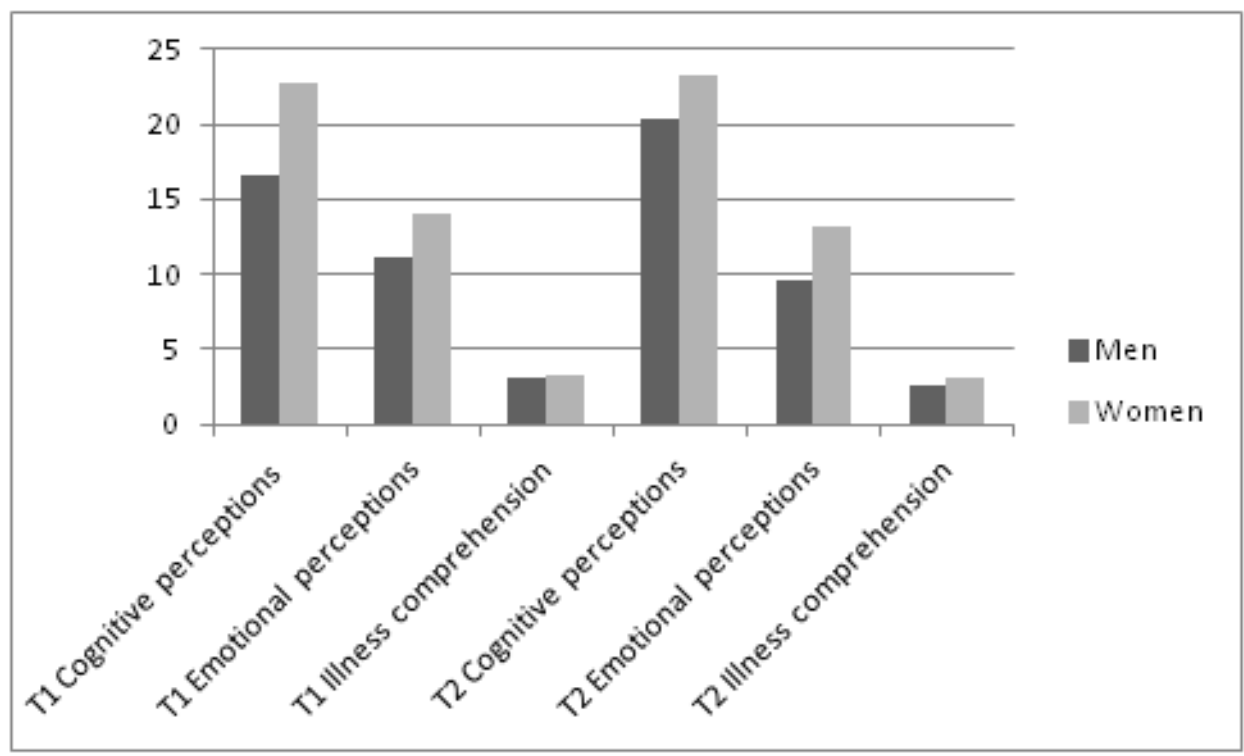

Figure 2. Average comparison (independente $t$-test) of cognitive and emotional perception and illness comprehension in patients with cancer according to gender in T1 and T2 $(n=50)$.

Regarding the open question of the IPQ-R (item 9) which investigates perceptions of possibles cancer causes, categories extracted from the answers were: (a) cancer was originated by stress; (b) emotional causes (sadness, anger, relationship problems in the course of life); (c) genetic or hereditary causes (disease affecting close relatives); (d) accidents (external or environmental events that caused physical damage which, in term, would develop cancer); (e) bad health habits (wrong feeding habits, sedentarism, smoke); (f) mystical or religious causes ("divine punishment", "karma"); (g) work related causes (exposure to toxic agents); (h) other causes; and (i) Do not know/do not exist. For purposes of analysis in this study, it was considered that patients first answer would be the most important cause, since many of them did not provide another answer. Figure 3 shows the answers distribution in a general way. In T1, the most frequent cancer cause referred by the participants was emotional causes (12 answers), followed by bad health habits (11) and genetic/hereditary (10). In T2, the most frequent answer about cancer cause was related to the category genetic/ hereditary (11), followed by the categories bad health habits and stress (both with 8). Chi-square tests showed that changes in the answers of patients in twelve months (T1 and T2) were statistically significant $\left(\mathrm{X}^{2}=135.526 ; p<.001\right)$.
When compared the changes in causes of cancer perceptions separatly between man and women, it was found that they ocurred more frequently in women $\left(\mathrm{X}^{2}=77.238\right.$, $p<.01)$ than in men $\left(\mathrm{X}^{2}=48.828, p<.10\right)$.

Likewise, it was compared the perception about cancer in $\mathrm{T} 1$ and $\mathrm{T} 2$ dividing the patient in groups with and without methastasis, with and whithout family cancer history, and patients who had or had not chemotherapy, radiotherapy and surgery in the past year. The results of those analysis did not reveal significant differences between groups. Comparison between patients with different types of cancer was not possible due to the huge differences in diagnosis within that sample.

\section{Discussion}

The main purpose of the study, with longitudinal design, was to examine illness perception in young adults with cancer, comparing possible differences between men and women. In this sense, in a general way, it was observed little significant changes on illness perception in a period of one year, however, there were found important differences on the illness perception when compared men and women.

Few significant differences on illness perceptions in the period showed that, in the contrary of the idea presented 


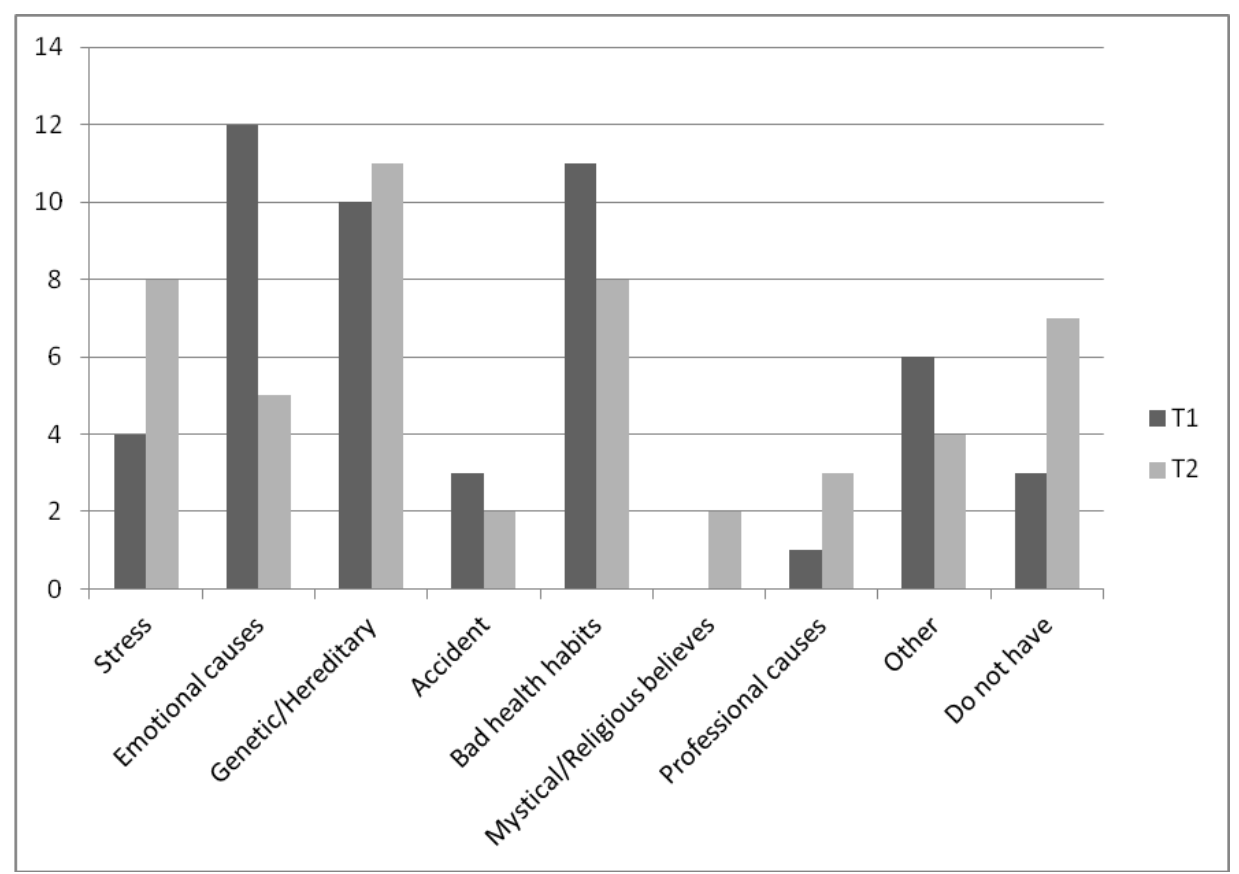

Figure 3. Frequencies of answers about perception of cancer causes in T1 and T2 $(n=50)$.

in the study of Llevellyn et al. (2007), perception are not always as dynamic and able to be change just by the course of the disease and its treatment. The only changes found in the period were related to the believes about the possible cancer causes. Specially, increased the frequence of categories stress and genetic/hereditary and diminished the believes in emotional causes and bad health habits.

It is possible that chronic illness timeline and the fact that those patients did not receive psychological specific attention to deal with questions related to the illness and treatment have not made possible more significant changes in their way of thinking about cancer and its treatment. Moreover, specific characteristics of the sample in this study, such as low age of the patients and low schoolarity may have contributed for this results. It was highlighted the high frequency of emotional causes category in the question which investigated illness causality perceptions, specially in $\mathrm{T} 1$. That kind of answers shows distorted ideas (even unrealistic) about the origin of cancer since, independently of the kind, the cause is always multifactorial (Instituto Nacional do Câncer [INCA], 2010). Besides the low schoolarity already referred, possible communication difficulties with the health team and of comprehension about the disease may have colaborated for those equivocal thoughts. Maybe with the course of the disease and its treatment and the acquired experience about it, some patients have understood, somehow, the complexity of the disease and, therefore, changed their opinion about the causes.

About the differences found on the perception of men and women with cancer, the presence of significant differences between those two groups of patients deserves to be highlighted, specially because those peculiarities have changed from T1 to T2. In T1 women had bigger levels of negative cognitive perceptions than men in a significant way, in T2 those patients showed bigger levels of emotional perceptions. These results point, therefore, that in $\mathrm{T} 2$ men raised their levels of cognitive perception about cancer, showing that the thoughts about less control of the disease, treatment and cure ocurred in a more systematic way, reaching similar levels to the one's found in the women's group. That is an indication of a better adaptation to the disease, with lesser concern and negative emotional condition towards it.

Until now, existing studies which investigated cancer perception, all with samples from outside Brazil, did not bother or did not find differences between men and women (Anagnostopoulos \& Spanea, 2005; Jorgensen et al., 2009; Llevellyn et al., 2007; Millar et al., 2005; Rees et al., 2004; Scharloo et al., 2005). However, Gianini (2004), on a qualitative research carried out in São Paulo about relation between coping with cancer and gender, observed that men focus their actions on resolution of situational problems that show up during the development of the disease and its treatment, while women concern to search for emotional back up and social support to deal with the situation. According to the author, those differences are affected by gender roles that men and women perform in our society, where woman would be more senstive to emotional aspects and man better prepared to use reason.

Likewise, in the self-regulation model, illness perceptions are the basis of coping strategies $(\mathrm{H}$. Leventhal et al., 2003; H. Leventhal et al., 1984), those results are compatible with the one's found in this study. It can be inferred that men, with concern in solving specific problems 
Castro, E. K., Kreling, M., Ponciano, C., Meneghetti, B. M. \& Chem, C. M. (2012). Longitudinal Assessment of Illness Perceptions in Young Adults with Cancer.

and short-term of the illness, end up having less negative cancer perceptions and, possibly, also present a bigger perception control of their health which increases selfconfidence and self-efficacy in order to overcome the illness (Bandura, 2005; Castro, Ponciano, \& Pinto, 2010). In opposition, becoming emotionally shaken by the diagnosis, women could aim their thougths to mid and longterm life plans, generating more negative cancer perceptions and making their coping less effective.

Since the sample of this study has quite heterogeneous characteristics, it is possible that some of these peculiarities between men and women are more related to a specific type of cancer (such as breast cancer) than to gender. Another possibility of data interpretation could be the relation between cancer and illness visibility. Perhaps some types of cancer that cause more visible mutilations of the body, such as breast, head or neck cancer, may generate more negative illness perceptions than other less visible types of cancer (such as intestin, stomach cancer, etc.). Futures studies may confirm this issue.

The subjectivity of this concept is well shown by the fact that patients with methastasis or cancer family history, as well as those who went through certain kinds of treatment such as chemotherapy, radiotherapy and surgery, do not differ from others in relation to the illness representation. In fact, illness perception is very particular to each individual, since he considers his expectations and way of thinking (Leventhal et al., 2003; Leventhal et al., 1984). Therefore, it could be of interest to examine, in future studies, perceptions about illness characteristics and the kind of treatment carried out on patients to achieve a better comprehen-sion about this results.

Summarizing, it is very important to evaluate illness perceptions in cancer patients during treatment since they will provide very useful information to health professionals on how to deal with patients who have irrealistic or distorted beliefs about their sickness. In this sense, relative stability of these perceptions in the period of one year show that they can be independent of the increase in information about the disease acquired during the treatment experience. Therefore, would be interesting, not only to give to the patient better knowledge about cancer and its treatment and enhance the communication between patient and the health team, but also to promote psychosocial interventions in order to help them to reflect about their own perception and ways of coping with the disease.

This study has some limitations, such as it's performance of the study in a specific hospital, small number of individuals in the sample and its heterogeneity in what refers to types of cancer and types of treatment. Future researches could work with specific sub-samples to understand possible peculiarities in this perceptions according to the type of cancer, severity and time of diagnosis. Since this is a new subject and, still, quite unexplored within the
Brazilian reality, research brings important contributions by providing longitudinal data about cancer perceptions on patients with low schoolarity and on treatment by National Health System (SUS).

\section{References}

Anagnostopoulos, F., \& Spanea, E. (2005). Assessing illness representations of breast câncer: A comparison of patients with healthy and benign controls. Journal of Psychosomatic Research, 58, 327-334.

Bandura, A. (2005). The primacy of self-regulation in health promotion. Applied Psychology: An International Review, 54, 245-254.

Bardin, L. (1977). Análise de conteúdo [Content analysis]. Lisboa, Portugal: Edições 70.

Baucom, D. H., Porter, L. S., Kirby, J. S., Gremore T. M., \& Keefe, F. J. (2006). Psychosocial issues confronting young women with breast cancer. Breast Disease, 23, 103-113.

Broadbent, E., Petrie, K. J., Main, J., \& Weinman, J. (2006). The brief illness perception questionnaire. Journal of Psychosomatic Research, 60, 631-637.

Castro, E. K., Ponciano, C., \& Pinto, D. W. (2010). Autoeficácia e qualidade de vida de jovens adultos com doenças crônicas [Self-efficacy and quality of life in young adults with chronic disease]. Aletheia, 31, 137-148.

Covic, A., Seica, A., Gusbeth-Tatomir, P., Gavrilovici, O., \& Goldsmith, J. A. D. (2004). Illness representations and quality of life scores in hemodialysis patients. Nephrology Dialysis Transplantation, 19, 2078-2083.

Figueras, M. J., \& Marcelino, D. (2009). Exploring associations between illness perceptions and quality of life in tree chronic illness. Psychology \& Health, 24, 173.

Gianini, M. (2004). Câncer e gênero: Enfrentamento da doença [Cancer and gender: Coping with the disease]. (Dissertação de Mestrado não-publicada). Programa de Pós-Graduação em Psicologia Clínica, Pontifícia Universidade Católica de São Paulo, SP.

Heijmans, M., \& Ridder, D. (1998). Assessing illness representations of chronic illness: Explorations of their diseasespecific nature. Journal of Behavioral Medicine, 21, 485-503.

Instituto Nacional do Câncer. (2010). Câncer. Retrieved July 05, 2010, from http://www.inca.gov.br/conteudo view. asp?id=326

Jorgensen, I. L., Frederiksen, K., Boesen, E., Elsass, P., \& Johansen, C. (2009). An exploratory study of associations between illness perceptions and adjustment and changes after psychosocial rehabilitation in survivors of breast cancer. Acta Oncologica, 48, 1119-1127.

Kissane, D. W., Grabsch, B., Love, A., Clarke, D. M., Bloch, S., \& Smith, G. C. (2004). Psychiatric disorder in women with early stage and advanced breast cancer: A comparative analysis. Psychiatric Disorder in Breast Cancer, 38, 320-326.

Leventhal, H., Brissete, I., \& Leventhal, E. A. (2003). The common-sense model of self-regulation of health and ilness. In L. D. Cameron \& H. Leventhal (Eds.), The self-regulation of health and ilness behaviour (pp. 42-65). London: Routledge. Leventhal, H., Nerenz, D. L., \& Steele, D. J. (1984) Illness representation and coping with health threats. In A. Baum, S. E. Taylor, \& J. E. Singer (Eds.), Handbook of Psychology and Health: Vol. IV. Social psychological aspects of health (pp. 219-253). Hillsdale, NJ: Erlbaum. 
Llevellyn, C. D., McGurk, M., \& Weinman, J. (2007). Illness and treatment beliefs in head and neck cancer: Is Leventhal's common sense model a useful framework for determining changes in outcomes over time? Journal of Psychosomatic Research, 63, 17-26.

Millar, K., Purushotham, A. D., McLatchie, E., George, W. D., \& Murray, G. D. (2005). A 1-year prospective study of individual variation in distress, and illness perceptions, after treatment for breast cancer. Journal of Psychosomatic Research, 58, 335-342.

Moss-Morris, R., Weinman, J., Petrie, K. J., Horne, R., Cameron, L. D., \& Buick, D. (2002). The revised illness perception questionnaire (IPQ-R). Psychology \& Health, 17, 1-16.

Petrie, K. J., \& Weinman, J. (2006). Why illness perceptions matter. Clinical Medicine, 6, 536-539.

Rees, G., Fry, A., Cull, A., \& Sutton, S. (2004). Illness perceptions and distress in women at increased risk of breast cancer. Psychology \& Health, 19, 749-765.

Rozema, H., Völlink, T., \& Lechner, L. (2009). The role of illness representations in coping and health of patients treated for breast cancer. Psycho-Oncology, 18, 849-857.

Scharloo, M., de Jong, R. J. B., Langeveld, T. P. M., VelzenVerkaik, E., den Arkeer, M. D., \& Kaptein, A. A. (2005). Quality of life and illness perceptions in patients with recently diagnosed head and neck cancer. Head \& Neck, 27, 857863.

Shaw, C. (1999). A framework for the study of coping, illness behaviour and outcomes. Journal of Advanced Nursing, 29, 1246-1255.

Shiloh, S. (2006). Illness representatins, self-regulation, and genetic counseling: A theoretical review. Journal of Genetic Counseling, 15, 325-337.

Weinman, J., Petrie, K. J., Moss-Morris, R., \& Horne, R. (1996). The Illness Perception Questionnaire: A new method for assessing illness perceptions. Psychology \& Health, 11, 431-446. 